Document downloaded from:

http://hdl.handle.net/10251/161388

This paper must be cited as:

Guardiola, C.; Pla Moreno, B.; Real, M.; Travaillard, C.; Dambricourt, F. (2020). Fuel-to-air ratio control under short-circuit conditions through UEGO sensor signal analysis.

International Journal of Engine Research. 21(9):1577-1583.

https://doi.org/10.1177/1468087418820747

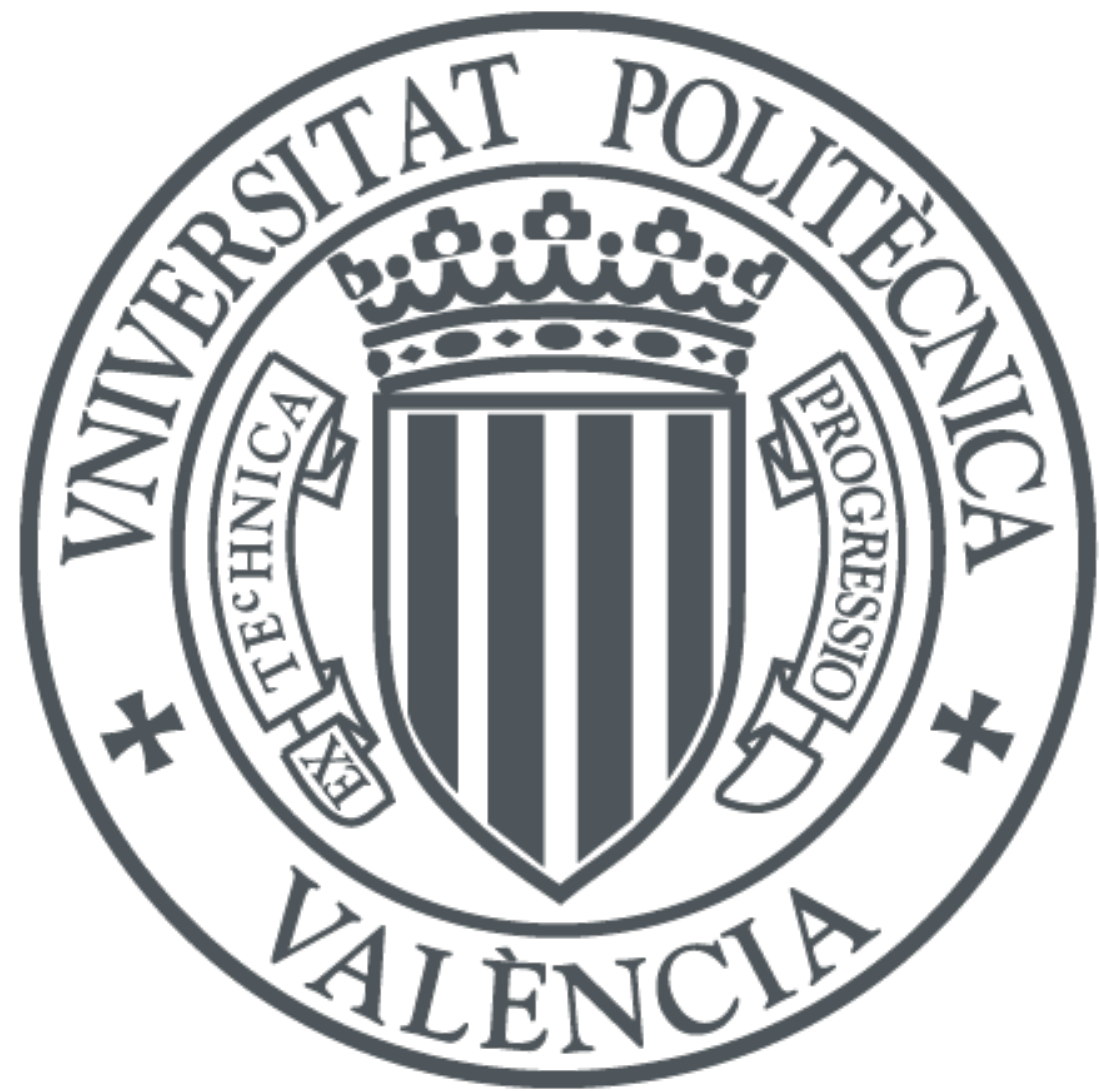

The final publication is available at

https://doi.org/10.1177/1468087418820747

Copyright SAGE Publications

Additional Information 


\title{
Fuel-to-air ratio control under short-circuit conditions through UEGO signal analysis
}

\author{
Carlos GUARDIOLA ${ }^{1}$, Benjamín PLA ${ }^{1}$, Marcelo REAL ${ }^{1}$, Cyril TRAVAILLARD ${ }^{2}$ and Frederic \\ DAMBRICOURT $^{2}$
}

\begin{abstract}
The impact of short-circuit (SC) pulses on the aftertreatment system of a spark ignited (SI) engine must be taken into account to keep the fuel-to-air equivalence ratio (FAR) within the three-way catalyst (TWC) window, thereby reducing pollutant emissions. The FAR overestimation that suffers the wide range $\lambda$-sensor upstream TWC in the presence of SC is especially relevant. In this study a novel approach to deal with FAR control under SC conditions is introduced. Under this scope, the present work proposes a strategy for the on-board correction of the aforementioned FAR overestimation, by means of the information regarding to SC level that provides the frequency content of the $\lambda$-sensor at the engine frequency. Finally, the potential of this approach to minimise pollutant emissions, in particular the NOx penalty arisen as a consequence of running the engine at leaner conditions than expected, is assessed through experimental tests.
\end{abstract}

\section{Keywords}

Spark ignited engine, Fuel-to-air ratio control, Three-way catalyst, Short-circuit, Emissions control

\section{Introduction}

With the popularization of small turbocharged and spark ignited (SI) engines, the low-end torque issues have grown in prominence in the last few years, thus, the use of scavenging strategies to increase torque at low engine speed has been extended. The effect of fresh air Short-Circuit (SC) on $\lambda$-sensor and three-way catalyst (TWC) performance is pointed out in previous works ${ }^{1}$. In the present paper, authors deal with the control of the fuel-to-air equivalence ratio (hereinafter FAR for simplicity) under SC conditions in order to minimise its negative impact on NOx emissions. Note that little is published on this issue since SC is only actively used at low engine speed and high load conditions, which is a very particular operating area. Nevertheless, today it seems very convenient to address the issue of emission control under SC conditions due to the intensive use of small turbocharged engines that tends to work on this conditions more often ${ }^{2-5}$.

Typically, state-of-the-art engines have a wideband $\lambda$ sensor upstream and a switch type $\lambda$-sensor downstream of the TWC. The second one is mainly used for two purposes: OBD and closed-loop control at some operating conditions, mainly steady state. Due to the strong non-linearity of that type of sensor, as well as to the storing dynamics of the TWC, the controller must be very slow. Otherwise, the action of the closed-loop control (downstream of the TWC) could cause FAR instabilities. Under transient conditions, the FAR disturbances caused by the different path of fresh air and fuel, like intake manifold dynamics, wall-wetting or short-circuit, exceed the capabilities of the downstream closed-loop control ${ }^{6,7}$.

As it is well known, the closed-loop FAR control by using the feedback provided by the wideband $\lambda$-sensor upstream of the TWC is the typical approach without shortcircuit, that is, in normal operation ${ }^{8-18}$. However, when a gasoline direct injection engine is operated under shortcircuit (SC) conditions, the FAR upstream TWC tends to be leaner as the percentage of SC increases (if in-cylinder FAR is kept stoichiometric), which is not acceptable from the pollutant emissions point of view, due to the behavior of the TWC (NOx emissions at lean conditions). Thus, stoichiometric FAR at TWC inlet is needed even under $\mathrm{SC}$ conditions. This means that in-cylinder FAR must be

\footnotetext{
${ }^{1}$ CMT-Motores Térmicos, Universitat Politècnica de València, Valencia, Spain

${ }^{2}$ PSA Peugeot Citroën, La Garenne-Colombes, France
}

\section{Corresponding author:}

Marcelo REAL, Camino de Vera, s/n 46022 Valencia, Spain

Email: marreami@mot.upv.es 
richer as SC increases in order to compensate for the fresh air pulses and getting stoichiometric FAR at TWC inlet. The issue is that, under this conditions, the wideband $\lambda$ sensor upstream of the TWC tends to overestimate the FAR, which disables this sensor to provide a proper feedback for the closed-loop control. To take actions about FAR control under SC conditions and therefore to avoid negative effects on the after-treatment system, all the possible solutions pass through an estimation of the SC rate. Of course, if $\mathrm{SC}$ is known, the proper correction of the wide-range $\lambda$-sensor signal may be addressed in order to counteract its effect. One feasible choice goes through mapping the appropriate offset to increase the FAR provided by the $\lambda$ sensor depending on SC. Nevertheless, if SC is just mapped depending on operating conditions, the success of such an approach relies on the accuracy of the calibration and it is subjected to the impact of ageing or any other disturbance, as it happens with all systems based on static calibrations. Controlling with a wideband $\lambda$-sensor downstream the TWC under SC conditions would be another possibility, since the catalyst filters the SC pulses. But then, the TWC dynamics and the effect of the exhaust gas composition downstream the catalyst on the $\lambda$-sensor must be taken into account ${ }^{19}$.

The present paper shows a brief review of the main SC effects on FAR control in section 2. Section 3 describes the engine, test bench and other facilities used. Next, section 4 points out the SC effect on $\lambda$-sensor. Then, section 5 proposes a strategy for instantaneous on-board SC estimation, by using the frequency content of the $\lambda$-sensors signal upstream TWC. The validation of the introduced strategy is carried out in section 6 . Finally, section 7 summarizes the main contributions of this paper.

\section{Problem description}

SC effect on the TWC of SI engines can be mainly explained as the superposition of two simultaneous phenomena, one of them related to the $\lambda$-sensor and the other one associated with the TWC, both quantitatively dependent on SC amount. On the one hand, $\lambda$-sensor upstream catalyst tends to overestimate the actual FAR under SC conditions, presumably because of the impact on the in-cycle dynamics of exhaust gases composition generated by SC pulses.

On the other hand, the fact that in-cylinder FAR affects the generation of the main pollutant species, that is, $\mathrm{CO}$, NOx and HC, leads to important changes in the exhaust gas concentration of these species at TWC inlet, when stoichiometric FAR is imposed in the presence of SC. Under these circumstances the TWC is forced to operate simultaneously with fresh air and residual gases whose composition is typical of rich combustion. In order to keep
Table 1. Engine set up.

\begin{tabular}{ll}
\hline Bore $\times$ Stroke & $75 \mathrm{~mm} \times 90.5 \mathrm{~mm}$ \\
Number of cylinder & 3 \\
Total displacement & $1199.9 \mathrm{~cm}^{3}$ \\
Compression ratio & $10.5: 1$ \\
Maximum power & $96 \mathrm{~kW} @ 5500 \mathrm{rpm}$ \\
Maximum torque & $230 \mathrm{Nm} @ 1750-3500 \mathrm{rpm}$
\end{tabular}

stoichiometric FAR at TWC inlet with SC, a fairly rich FAR at the cylinder is necessary, which leads to high HC and $\mathrm{CO}$ emissions at the TWC inlet. Comparing to an operating point with the same FAR but without SC, the prime consequence of SC experimentally observed is the improvement of NOx efficiency together with the decrease of $\mathrm{CO}$ oxidation capabilities. In this sense the TWC window i.e., the optimal FAR range for TWC performance, is moved on to slightly leaner conditions.

Although the effects explained above behave in an opposite way, it is important to highlight that their consequences do not counteract themselves reciprocally as it is shown in figure 1. In this figure, three different approaches have been implemented while making a SC swept. Light circles corresponds to keeping constant the FAR provided by the $\lambda$-sensor $\left(\mathrm{FAR}_{\lambda}\right)$; as $\mathrm{SC}$ increases $\lambda$-sensor overestimates progressively the actual FAR and TWC operates at leaner conditions, the aftereffect is a noticeable increase in NOx emissions. Dark circles display the consequence of keeping constant the FAR provided by the gas analyser $\left(\mathrm{FAR}_{G A}\right)$; the reductant species at the TWC inlet rises with the increase of incylinder FAR (FAR $\mathrm{CYL}_{\mathrm{L}}$ ), thus the TWC window moves to leaner conditions and $\mathrm{CO}$ emissions increases with $\mathrm{SC}$ raise. Finally, black circles are the result of imposing the optimum FAR in order to minimise the pollutant emissions (addition of CO and NOx), which means to operate with a FAR within the previous cases to compensate both effects.

Under this scope, the on-line estimation of the instantaneous amount of SC could be really helpful to improve the FAR control. The present paper proposes an approach to deal with this issue with the focus on the pollutant emissions reduction.

\section{Experimental set up}

The engine is a state-of-art 3-cylinder turbocharged GDI with a displacement of 1.2 litres. Table 1 shows its main features.

Considering that TWC is the main element of the aftertreatment system, it has been especially instrumented in order to measure pressure, temperature, gas composition and FAR with $\lambda$-sensors at the inlet and outlet. Two exhaust 



Figure 1. SC effect on $\lambda$-sensor and TWC window. Top to Bottom: NOx emissions; CO emissions; FAR provided by gas analyser; FAR provided by $\lambda$-sensor.

gas analysers, Horiba MEXA-ONE and Cambustion NDIR500 Fast $\mathrm{CO}_{2} \mathrm{CO}_{2}$, have been used to quantify the concentration of the different species. The main advantage of the last one is the sampling frequency that allows to capture transient evolutions besides steady measurements. An encoder is also used to synchronize these measurements with the crank angle. Additionally, pressure and temperature sensors complete the engine instrumentation at the inlet and outlet of each element along intake and exhaust lines.

Since working in the presence of SC is not feasible in all the engine operating conditions, the selected point to carry out all the test is $1750 \mathrm{rpm}$ and $65 \%$ load, that is, one belonging to low engine speed and high load area. Under these conditions, the air mass flow and fuel consumption are $90 \mathrm{~kg} / \mathrm{h}$ and $6.4 \mathrm{~kg} / \mathrm{h}$ respectively, while the engine provides a torque of $140 \mathrm{Nm}$. In order to keep the TWC
Table 2. Predefined valve overlap levels

\begin{tabular}{cccc}
\hline $\begin{array}{c}\text { Valve } \\
\text { Overlap }\end{array}$ & $\begin{array}{c}\text { Waste } \\
\text { Gate }\end{array}$ & Nomenclature & $\begin{array}{c}\text { Measured } \\
\text { SC rate }\end{array}$ \\
\hline$-21^{\circ}$ & $100 \%$ & $\mathrm{a}$ & $0.0 \%$ \\
\hline $24.9^{\circ}$ & $44 \%$ & $\mathrm{~b}$ & $0.8 \%$ \\
\hline $37.6^{\circ}$ & $43 \%$ & $\mathrm{c}$ & $1.9 \%$ \\
\hline $50.2^{\circ}$ & $40.5 \%$ & $\mathrm{~d}$ & $3.7 \%$ \\
\hline $59.9^{\circ}$ & $39 \%$ & $\mathrm{e}$ & $5.6 \%$ \\
\hline $69.6^{\circ}$ & $37.5 \%$ & $\mathrm{f}$ & $7.5 \%$ \\
\hline $80.1^{\circ}$ & $36 \%$ & $\mathrm{~g}$ & $9.5 \%$ \\
\hline
\end{tabular}

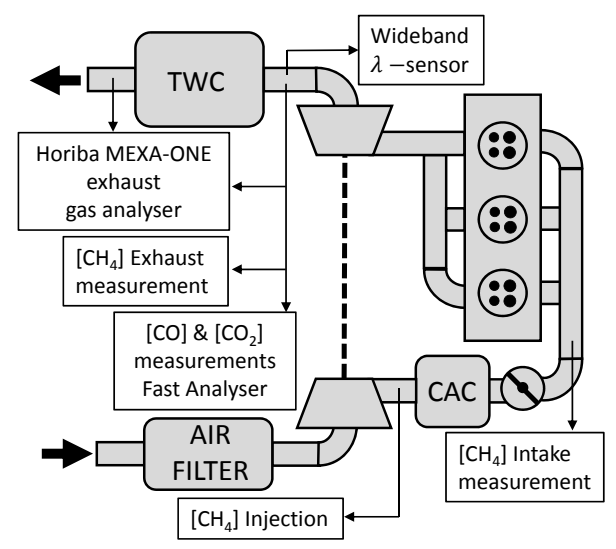

Figure 2. Engine instrumentation diagram

under its thermal limits, the SC applied ranges from zero up to $10 \%$. The nomenclature used hereinafter to refer the different overlap levels is shown in Table 2.

The tracer gas method ${ }^{20-23}$ has been used to experimentally quantify the air mass short-circuited, particularly, the gas employed is $\mathrm{CH}_{4}$. From the methane measurements, $\mathrm{SC}$ is calculated as follows:

$$
S C=\frac{\left(\left[\mathrm{CH}_{4}\right]_{w / i n j}-\left[\mathrm{CH}_{4}\right]_{w / o \text { inj }}\right)^{e x h}}{\left(\left[\mathrm{CH}_{4}\right]_{w / i n j}-\left[\mathrm{CH}_{4}\right]_{w / o \text { inj }}\right)^{i n t}}
$$

where the term $\mathrm{CH}_{4}$ refers to the methane concentration, indexes $_{w / i n j}$ and ${ }_{w / o} i n j$ represent tests with and without methane injection respectively and the indexes ${ }^{i n t}$ and ${ }^{e x h}$ stand for engine intake and exhaust manifolds.

\section{SC effect on $\lambda$-sensor}

Taking into account the sensitivity of the lambda sensor to the SC, the present paper proposes to analyse the lambda sensor signal in two different time scales to estimate both the FAR and the SC.

In this sense, figure 1 shows the effect of the SC on the lambda sensor signal while, figure 3 show that, SC pulses involve a characteristic waveform in the lambda sensor 


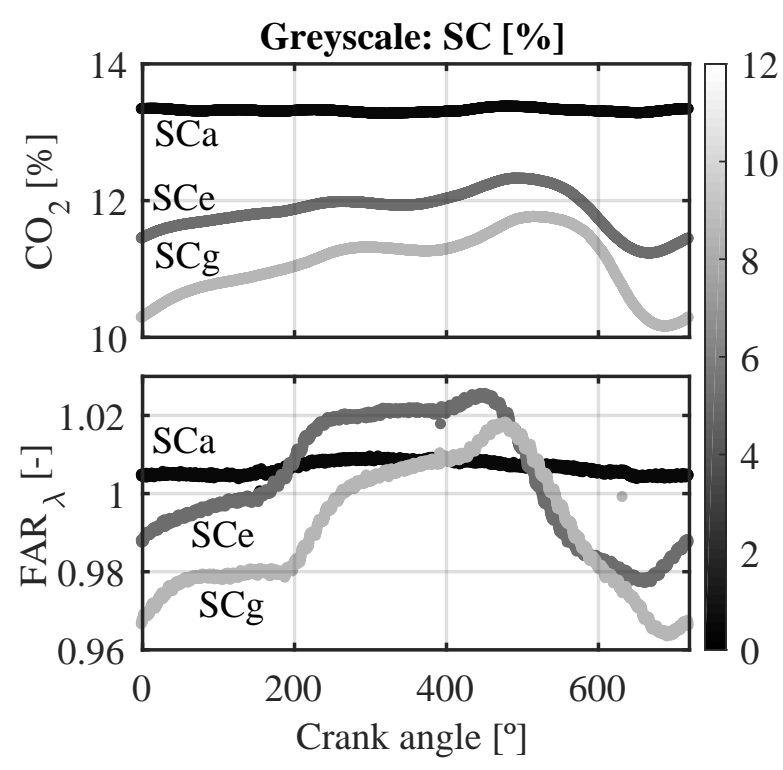

Figure 3. In-cycle averaged $\mathrm{CO}_{2}$ and $\lambda$ waveforms measured for each predefined SC.

signal during each engine cycle. The plot at the top of figure 3 displays the $\mathrm{SC}$ effect on in-cycle raw $\mathrm{CO}_{2}$ concentration, $\mathrm{SC}$ fresh air pulses tend to dilute the residual combustion gases, therefore the average $\mathrm{CO}_{2}$ concentration decreases with SC increase, appearing a characteristic waveform because of the gases transport through the asymmetrical exhaust manifold (figure 2). Similarly, the FAR provided by the $\lambda$-sensor at the exhaust (bottom plot) also presents a waveform when SC increases, but in this case the in-cycle average value is kept constant due to the SC effect on the sensor and the fact that a closed loop control is carried out. Then, the $\lambda$-sensor signal content at the engine frequency may be used to estimate the SC, while the signal content at low frequencies provides a first estimation of the FAR that can be corrected with the value of SC and the relation shown in figure 1.

\section{SC effect correction strategy}

The scheme of the proposed strategy is shown in figure 4 . With the $\lambda$-sensor signal, the amplitude of the frequency content at engine frequency $\left(\widehat{A}_{\lambda, f 0}\right)$ can be calculated via Discrete Fourier Transform (DFT) as follows:

$$
\widehat{A}_{\lambda, f 0}=\left|D F T_{k}\left(f_{0}\right)\right|_{k=1}^{K}
$$

with:

$$
\operatorname{DFT}_{k}\left(f_{0}\right)=\frac{2}{t_{N}^{k}} \sum_{n=1}^{N} \widehat{x_{n}^{k}} e^{\left(-2 \pi i f_{0} \widehat{t_{n}^{k}}\right)}
$$

where:

$f_{0} \Rightarrow$ engine frequency.

$\widehat{x_{n}^{k}} \Rightarrow$ element $n$ in the $\lambda$-sensor signal window $k$.

$N \Rightarrow$ window size.

$p=N\left(1-\frac{\text { window overlapping }[\%]}{100}\right)$

$L \Rightarrow$ signal size.

$K \Rightarrow$ number of windows $=\frac{L-N}{p}$

$\widehat{t_{n}^{k}} \Rightarrow$ element $n$ in the time window $k$.

Note that the complete spectrum is not needed, just the engine cycle harmonic must be calculated. The computational cost of the proposed method is not too demanding and its main advantage is that just a timebased sampling is needed. Of course, if the sampling at crank angle domain is available, another approaches exist with even less computational demand for on-board DFT calculation as the one shown in ${ }^{24,25}$. In such case, the DFT can be calculated in real-time by using a circular buffer in which storing the samples of the signal, in order to calculate the DFT as from its value in the previous step ${ }^{26}$. The size of the buffer must contain an integer number of engine cycles, and the sampling frequency must be proportional to the engine speed. The buffer must be filled orderly, substituting the old samples with the new ones, allowing the calculation of the frequency content of the signal for the corresponding harmonic.

Next, the previous signal $\left(\widehat{A}_{\lambda, f 0}\right)$ can be used to estimate the $\mathrm{SC}$ with the aid of an experimental correlation, in which the actual SC has been measured by means of tracer gas method at steady state, for example. Once the instantaneous $\mathrm{SC}$ is known, $\lambda$-sensor overestimation can be corrected by using the experimental correlation shown in figure 1 (bottom plot), where FAR error $(\triangle \mathrm{FAR})$ is calibrated as function of SC. Finally, the FAR error estimation can be applied over the FAR value provided by the $\lambda$-sensor to get the actual FAR.

\section{Results and discussion}

The SC estimation based on the $\lambda$-sensor has several advantages in comparison with the tracer gas method. On the one hand, it is not intrusive since no reacting substances may be introduced. On the other hand, it allows to obtain the dynamic evolution of the SC at transient conditions, while the gas analyser time response prevents from a proper dynamic evolution. In addition, the $\lambda$-sensor is available in all the automotive SI engines, thus the SC estimation could be done online, in contrast to tracer gas method that needs complex and expensive experimental facilities.

Figure 5 shows how the correlation between SC measured with tracer gas method and the amplitude of 


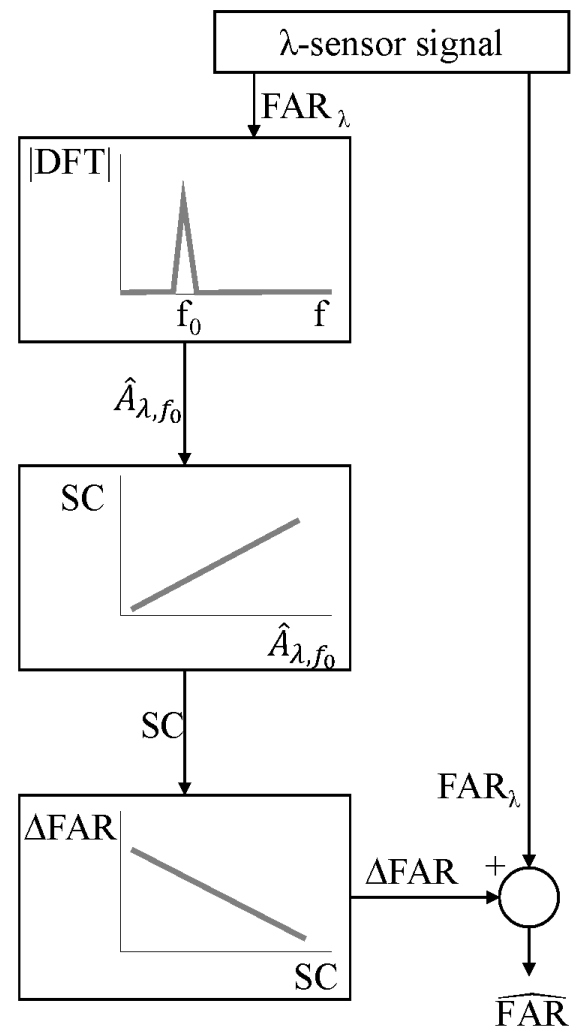

Figure 4. Proposed strategy to avoid the SC effect on the FAR control.

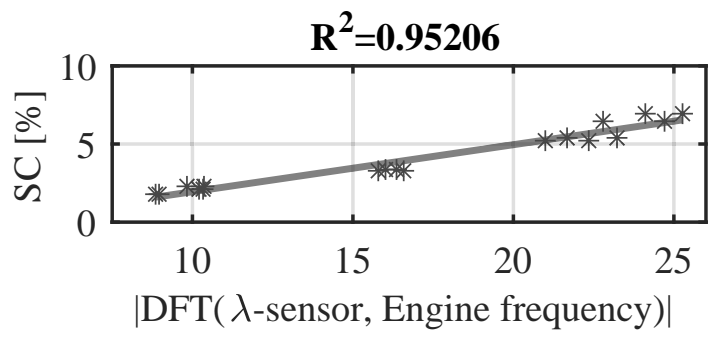

Figure 5. Correlation between SC measured with tracer gas method and amplitude of the instantaneous frequency content at engine frecuency of $\lambda$-sensor signal.

the harmonic corresponding to the engine frequency for $\lambda$ sensor signal, fits quite well for a linear approximation, at least in the $\mathrm{SC}$ range tested.

As first approach, for the implementation of this methodology the SC estimation via $\lambda$-sensor has been calculated offline. The test shown in figure 6 consist on the transition from valve overlap levels "d" to "e" in two different ways. First (black lines), keeping constant the FAR provided by the $\lambda$-sensor around the optimum value for SC level "d" in terms of emissions. Next (gray lines), the test is repeated but the FAR is corrected with the proposed method to take into account the $\lambda$-sensor overestimation with SC increase. The SC evolution during the transition from "d" to "e" is displayed for both the SC measurement with tracer gas method (dashed line) and the SC estimation provided by the $\lambda$-sensor (continuous line).

Of course, the SC evolution measured with tracer gas method is not useful for on-board control purposes, since it needs the simultaneous measurement of $\mathrm{CH}_{4}$ at intake and exhaust with and without $\mathrm{CH}_{4}$ injection. Moreover, the gas analyser imposes an important delay as displays the top plot in figure 6. In this test, the valve overlap evolution is sequential, increasing gradually the exhaust valve closing retard and next opening slightly the waste gate to keep constant the engine load. Thus both SC measurement (tracer gas method) and estimation (frequency analysis of $\lambda$-sensor) are totally consistent with the actuators operation, from "d" SC rises instantaneously when the overlap increases, then $\mathrm{SC}$ is reduced due to the waste gate operation, since the pressure difference between intake and exhaust drops off slightly, given as a result the SC at "e".

Regarding the case with FAR correction, the test shows how FAR has an impact on SC level for the same valve overlap, particularly SC is lower when FAR rises according to SC measurement and estimation. It is due to the fact that in-cylinder FAR $\left(\mathrm{FAR}_{\mathrm{CYL}}\right)$ drives the combustion temperature, as shows figure 7, where the normalized exhaust temperature is plotted on the $\mathrm{FAR}_{\mathrm{CYL}}-\mathrm{FAR}_{\mathrm{GA}}$ map. Maximum temperatures are reached with $\mathrm{FAR}_{\mathrm{CYL}} \approx$ 1 independently on the exhaust FAR $_{\mathrm{GA}}$ provided by the gas analyser. As a consequence, the turbocharging compression ratio $\left(r_{C}\right)$ decreases when exhaust temperature $\left(T_{3}\right)$ is reduced, pushed by rich $\mathrm{FAR}_{\mathrm{CYL}}$. Equation 3 shows the dependence between $T_{3}$ and $r_{C}$. The enrichment due to the FAR correction with SC involves a decline on exhaust temperature that leads to a reduction in the pressure difference between intake and exhaust, hence involving a slight reduction on the SC shown with both tracer gas and frequency analysis methods. That is why, compared with the case without FAR correction, SC decreases slightly when FAR increases to reach the proper TWC window, thereby, reducing $\mathrm{NO}_{\mathrm{x}}$ emissions.

$$
r_{C}=\left\{1+(1+F) C_{1} \frac{T_{3}}{T_{1}} \eta\left[1-\left(\frac{1}{r_{T}}\right)^{C_{2}}\right]\right\}^{C_{3}}
$$

where:

$r_{C}=\frac{P_{2}}{P_{1}} \Rightarrow$ compression ratio (compressor).

$r_{T}=\frac{P_{3}}{P_{4}} \Rightarrow$ expansion ratio (turbine).

$\eta=\eta_{C} \cdot \eta_{T} \cdot \eta_{m} \Rightarrow$ overall efficiency.

$T_{3} \Rightarrow$ turbine inlet temperature.

$T_{1} \Rightarrow$ compressor inlet temperature. 

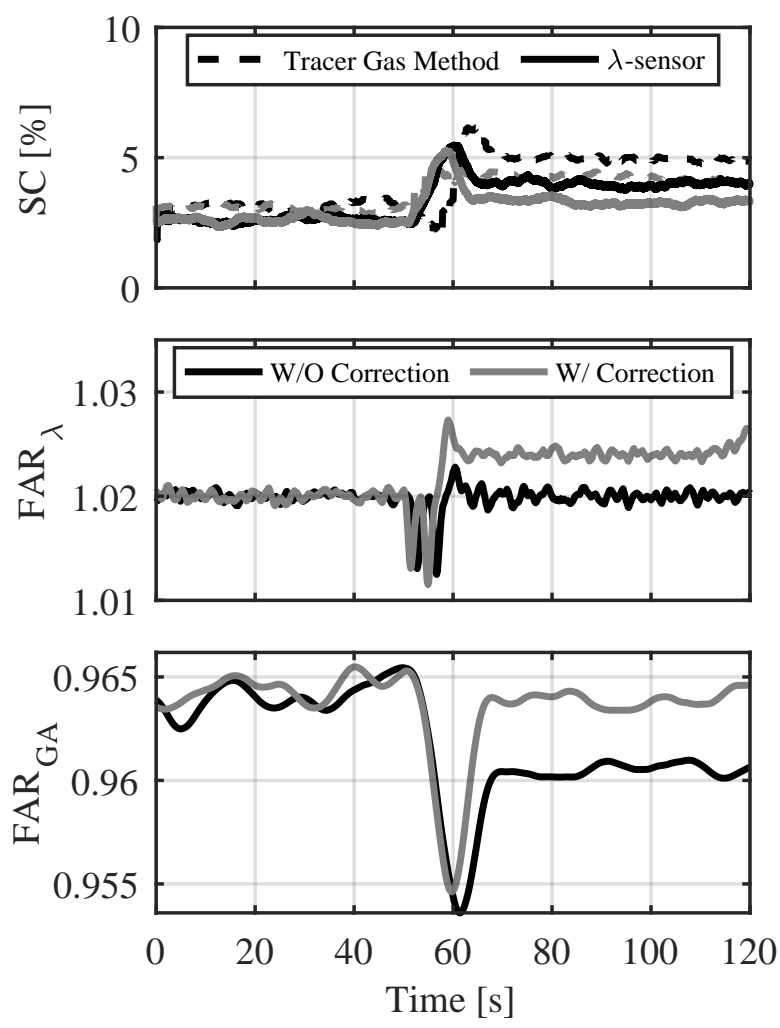

Figure 6. Top: SC measurement with tracer gas method (dashed lines) \& SC estimation with $\lambda$-sensor via DFT (continuous lines) for two different cases, that is, with \& without FAR correction (gray and black lines respectively); Center: FAR provided by the $\lambda$-sensor; Bottom: Actual FAR provided by the gas analyser

$$
C_{1}=\frac{c_{p_{T}}}{c_{p_{C}}} ; C_{2}=\frac{\gamma_{T}-1}{\gamma_{T}} ; C_{3}=\frac{\gamma_{C}}{\gamma_{C}-1}
$$

Finally, figures 8 and 9 show NOx and $\mathrm{CO}$ emissions upstream and downstream TWC respectively. According to the previous work of the authors ${ }^{1}$, raw emissions are mainly led by $\mathrm{FAR}_{\mathrm{CYL}}$, thus when $\mathrm{SC}$ rises and FAR upstream TWC is controlled in closed loop, $\mathrm{CO}$ and $\mathrm{NO}_{\mathrm{x}}$ increase and decrease respectively at engine exhaust as expected. In addition, it can be observed how despite upstream TWC emissions are quite similar by comparing the case with and without FAR correction, downstream TWC the $\lambda$-sensor overestimation causes an important penalty in $\mathrm{NOx}$ emissions when the effect of SC on $\lambda$-sensor is not corrected. In this sense, the FAR correction allows to keep the emissions almost constant around the optimum value after the SC step, avoiding the FAR overestimation produced by SC pulses on the $\lambda$-sensor.

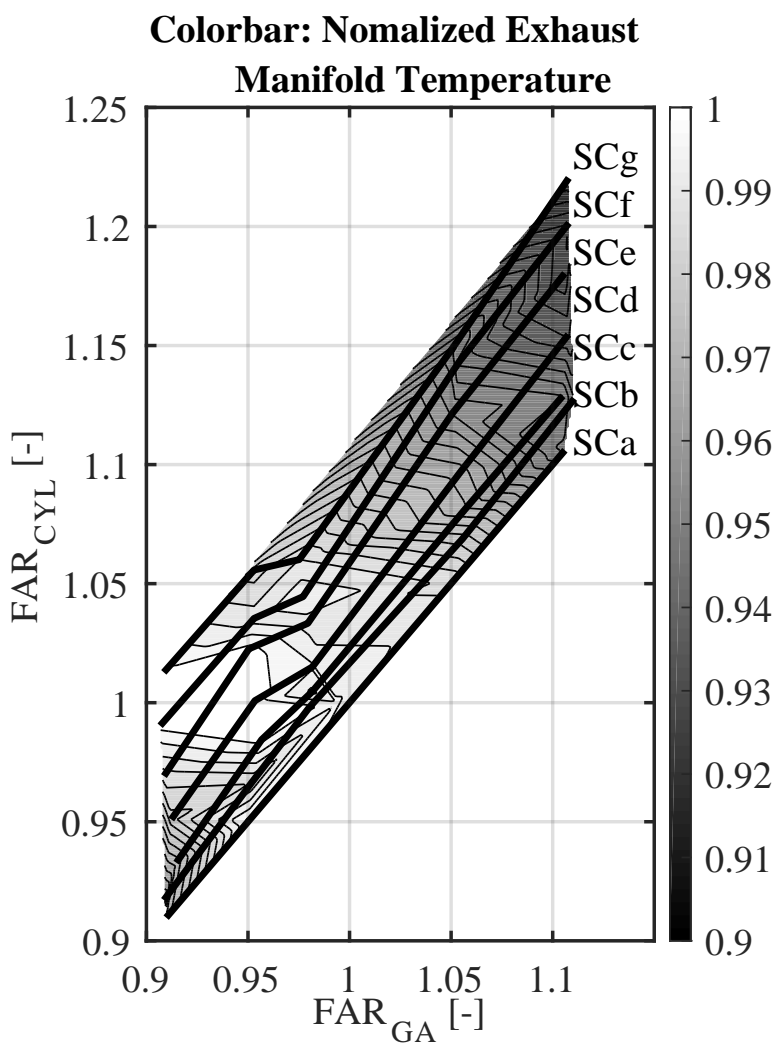

trim $=i$ left $_{i}$ ¡lower $i$ iright $i$ jupper $i$

Figure 7. FAR effect on exhaust temperature by comparing the $F_{A R A}$ provided by the gas analyser at the exhaust with the in-cylinder $F A R_{C Y L}$ for several overlapping levels.

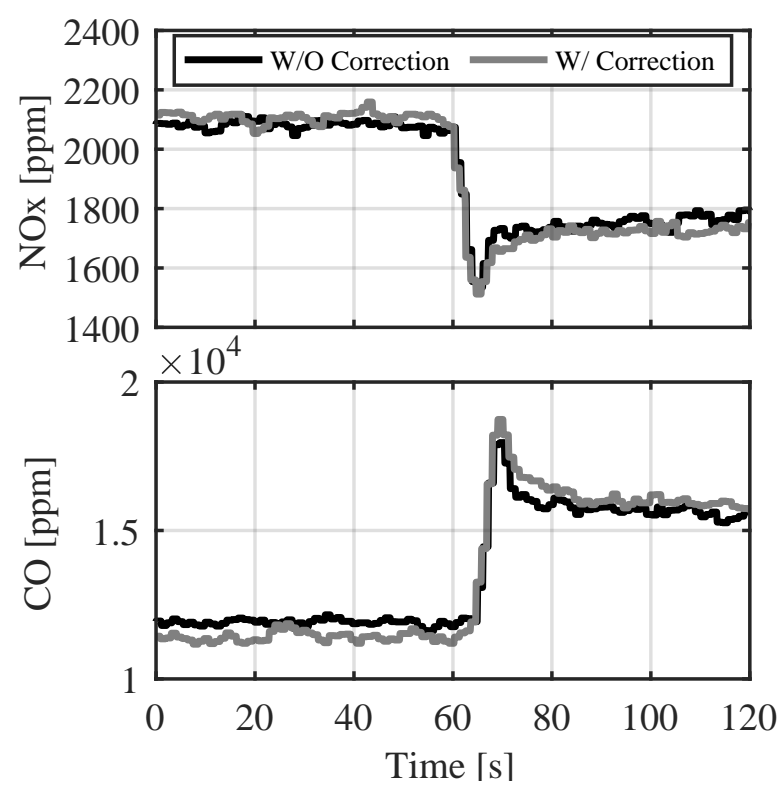

Figure 8. Top: NOx emissions upstream TWC; Bottom: CO emissions upstream TWC. 

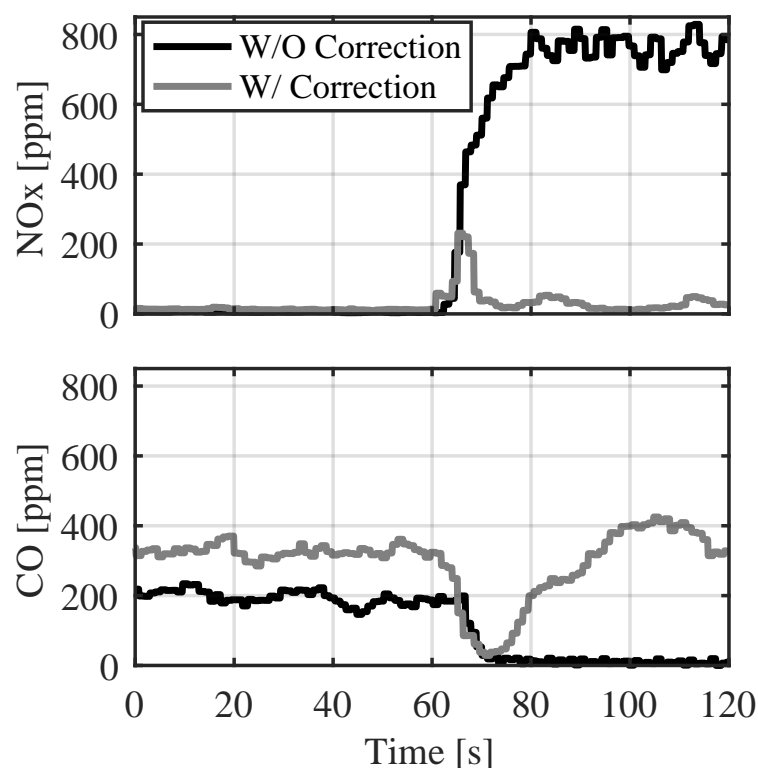

Figure 9. Top: NOx emissions donwstream TWC; Bottom: CO emissions downstream TWC.

\section{Conclusions}

Concerning to SC effects on after-treatment systems for SI engines, a correction to cope with the $\lambda$-sensor overestimation in the presence of SC has been proposed. The idea arises from the need to measure or at least estimate the SC on-board, in order to improve the FAR control under this circumstances beyond which it is allowed by mapping the $\mathrm{SC}$ as a static calibration.

The signal provided by the $\lambda$-sensor upstream TWC is employed for two different purposes. As usual, the content at low frequency allows measuring FAR. The amplitude of the $\lambda$-sensor signal at engine frequency, in turn, provides information related to the SC level. In this way, with the strategy proposed it could be feasible to correct online the FAR overestimation that appears when the engine runs under SC conditions.

Finally, the experimental tests carried out in this study highlight the potential of this approach to reduce pollutant emissions, especially NOx, since the FAR overestimation involve operating at leaner conditions than expected.

\section{Funding}

The authors acknowledge the support of Spanish Ministerio de Economía, Industria y Competitividad through project TRA2016-78717-R.

\section{References}

1. Guardiola C, Pla B, Real M et al. Short-circuit effects on spark ignition engine after-treatment and fuel-to-air ratio control. International Journal of Engine Research 2018; DOI: 10.1177/1468087418796705.

2. Martin S, Beidl C and Mueller R. Responsiveness of a 30 bar bmep 3-cylinder engine: Opportunities and limits of turbocharged downsizing. Technical Report No. 2014-011646, SAE Technical Paper, 2014.

3. Pagot A, Duparchy A, Gautrot X et al. Combustion approach for downsizing: the ifp concept. Oil \& gas science and technology 2006; 61(1): 139-153.

4. Ranini A and Monnier G. Turbocharging a gasoline direct injection engine. Technical Report No. 2001-01-0736, SAE Technical Paper, 2001.

5. Leduc P, Dubar B, Ranini A et al. Downsizing of gasoline engine: an efficient way to reduce $\mathrm{CO}_{2}$ emissions. Oil \& gas science and technology 2003; 58(1): 115-127.

6. Auckenthaler T. Modelling and Control of Three-way Catalytic Converters. PhD Thesis, Swiss Federal Institute of Technology Zurich, Switzerland, 2005.

7. Takubo H, Umeno $\mathrm{T}$ and Goto $\mathrm{H}$. New lambda-lambda airfuel ratio feedback control. Technical Report No. 2007-011340, SAE Technical Paper, 2007.

8. Turin RC and Geering HP. Model-based adaptive fuel control in an si engine. Technical Report No. 940374, SAE Technical Paper, 1994.

9. Powell JD, Fekete N and Chang CF. Observer-based air fuel ratio control. IEEE Control Systems 1998; 18(5): 72-83.

10. Guzzella L. Models and modelbased control of ic-engines-a nonlinear approach. SAE transactions 1995; : 1439-1447.

11. Roduner C, Onder C and Geering H. Automated design of an air/fuel controller for an si engine considering the threeway catalytic converter in the h? approach. In Proceedings of the fifth IEEE Mediterranean Conference on Control and Systems, Paphos, Cyprus.

12. Takiyama T, Shiomi E and Morita S. Air-fuel ratio control system using pulse width and amplitude modulation at transient state. JSAE review 2001; 22(4): 537-544.

13. Chang CF, Fekete NP, Amstutz A et al. Air-fuel ratio control in spark-ignition engines using estimation theory. IEEE Transactions on Control Systems Technology 1995; 3(1): 2231.

14. Shafai E, Roduner $\mathrm{C}$ and Geering HP. Indirect adaptive control of a three-way catalyst. Technical Report (No. 961038), SAE Technical Paper, 1996.

15. Balenovic M, Backx A and Hoebink J. On a model-based control of a three-way catalytic converter. Technical Report (No. 2001-01-0937), SAE Technical Paper, 2001.

16. Balenovic M, Backx T and De Bie T. Development of a model-based controller for a three-way catalytic converter. Technical Report (No. 2002-01-0475), SAE Technical Paper, 2002. 
17. Yildiz Y, Annaswamy AM, Yanakiev D et al. Spark ignition engine fuel-to-air ratio control: An adaptive control approach. Control Engineering Practice 2010; 18(12): 1369-1378.

18. Tomforde M, Drewelow W and Schultalbers M. Air-fuel ratio control with respect to oxygen storage dynamics. In Methods and Models in Automation and Robotics (MMAR), 2011 16th International Conference on. IEEE, pp. 242-247.

19. Germann H, Taglaiferri S and Geering HP. Differences in preand post-converter lambda sensor characteristics. Technical Report (No. 960335), SAE Technical Paper, 1996.

20. Olsen DB. Experimental and theoretical development of a tracer gas method for measuring trapping efficiency in internal combustion engines. $\mathrm{PhD}$ Thesis, Colorado State University, 1999.

21. Olsen DB, Hutcherson GC, Willson BD et al. Development of the tracer gas method for large bore natural gas engines. part i: Method validation. Journal of engineering for gas turbines and power 2002; 124(3): 678-685.

22. Schweitzer P. Scavenging of two-stroke cycle Diesel engines. Macmillan Co., 1949.

23. McGough MG and Fanick ER. Experimental investigation of the scavenging performance of a two-stroke opposed-piston diesel tank engine. Technical Report No. 2004-01-1591, SAE Technical Paper, 2004.

24. Macian V, Lujan JM, Guardiola C et al. DFT-based controller for fuel injection unevenness correction in turbocharged diesel engines. IEEE transactions on control systems technology 2006; 14(5): 819-827.

25. Macian V, Galindo J, Luján $J$ et al. Detection and correction of injection failures in diesel engines on the basis of turbocharger instantaneous speed frequency analysis. Proceedings of the Institution of Mechanical Engineers, Part D: Journal of Automobile Engineering 2005; 219(5): 691701.

26. García CG. Detección y compensación de irregularidades de inyección a través de la medida del régimen instantáneo del turbogrupo. Reverté, 2005. 